\section{A) Check for updates}

Cite this: Polym. Chem., 2019, 10 3497

Received 29th January 2019,

Accepted 31st March 2019

DOI: $10.1039 / c 9 p y 00147 f$

rsc.li/polymers

\title{
Bidirectional ROMP of paracylophane-1,9-dienes to tri- and penta-block $p$-phenylenevinylene copolymers $\dagger$
}

\author{
Venukrishnan Komanduri, (iD Dharam R. Kumar, Daniel J. Tate, (DD \\ Raymundo Marcial-Hernandez, Benjamin J. Lidster and Michael L. Turner (D)*
}

\begin{abstract}
Dialkoxy and dialkyl substituted paracyclophane-1,9-dienes undergo bidirectional ring opening metathesis polymerisation (ROMP) on addition of bifunctional Hoveyda-Grubbs initiators. The living nature of the polymerisation was demonstrated for different [monomer]/[initiator] ratios and block copolymers were prepared by sequential ROMP and ROMP-ATRP to give fully conjugated rod-rod-rod and partially conjugated coil-rod-coil ABA and BAB triblock copolymers, respectively. These strategies were successfully extended to the synthesis of the corresponding pentablock copolymers. Optical and electrochemical properties of cis/trans and all trans homo and block copolymers are discussed.
\end{abstract}

\section{Introduction}

$\pi$-Conjugated polymers have found extensive application as active layers in the fabrication of optoelectronic and electronic devices such as OLEDs, ${ }^{1}$ OFETs, ${ }^{2,3}$ OPVs $^{4,5}$ and sensors. ${ }^{6,7}$ Key advantages for the use of polymeric materials include improved flexibility, mechanical robustness, lighter weight and ease of processing. ${ }^{8}$ The performance of these devices is greatly influenced by the morphology of the active layer, and this is strongly influenced by the kinetics of thin film formation during device fabrication. An attractive approach to obtaining reproducible thin film morphologies is to utilise the thermodynamically driven phase separation of block copolymers, as these materials form well defined nanostructures that can be self-assembled in biphasic media. ${ }^{9,10}$ Block copolymers with conjugated segments can either be fully conjugated rodrod systems, in a diblock or rod-coil systems where the conjugated block is coupled to a saturated polymer backbone. ${ }^{11}$ There are only a few polymerisation methods that give welldefined fully conjugated block copolymers. These include Kumada catalyst-transfer polymerisation (KCTP also known as GRIM), ${ }^{12,13}$ a nickel catalysed Negishi type polymerisation ${ }^{14}$ and a palladium catalyst transfer Suzuki-Miyaura polycondensation. ${ }^{15}$ The synthesis of rod-coil systems has been more extensively reported, including the ROMP of cyclooctadiene

Organic Materials Innovation Centre (OMIC), The School of Chemistry, The University of Manchester, Oxford Road, Manchester, M13 9PL, UK.

E-mail:michael.turner@manchester.ac.uk

$\dagger$ Electronic supplementary information (ESI) available. See DOI: 10.1039/ c9py00147f followed by ATRP of the resulting macroinitiator. ${ }^{16}$ Phenylenevinylene (PPV) block copolymers can be prepared by the Siegrist polycondensation or by complex multistep syntheses. ${ }^{17,18,18}$ However these approaches lead to poor control of the molecular weight distribution and result in polymers with broad polydispersities $\left(D_{\mathrm{m}}\right)$ and significant backbone defects. $^{19}$

Ring opening metathesis polymerisation (ROMP) of strained paracyclophanedienes ${ }^{20-24,25}$ and cyclophanetrienes $^{26,27}$ gives well-defined PPV homopolymers and fully conjugated diblock copolymers. ${ }^{28,29}$ Rod-coil PPV diblock copolymers can be prepared by the sequential one-pot ROMP of tetraalkoxy paracyclophanediene and oxanorbornene monomers. ${ }^{30}$ This sequential ROMP strategy was adopted by Weck et al. using di, tetraalkoxy cyclophanedienes and norbornene ester monomers to access PPV tri and tetrablock copolymers. $^{31,32}$ A step-wise strategy using monotelechelic PPV blocks as macroinitiators for ATRP of methylmethacrylate gives rod-coil PPV-PMMA diblock copolymers. ${ }^{33}$ Rod-coil PPV block copolymers have also been prepared through the preparation of PPV macroinitiators using anionic polymerisation followed by the introduction of the coil unit using a radical polymerisation. ${ }^{34}$ However, to date there have been very few reports on the preparation of fully and partially conjugated PPV triblock copolymers. These include an ADMET polymerisation/ Wittig olefination strategy to prepare fully conjuagted ABA and ABCBA type PPV block copolymers ${ }^{35}$ and the synthesis of donor-acceptor-donor triblock copolymers by a Knoevenagel condensation followed by a Nickel catalysed Yamamoto coupling by Tu et al. ${ }^{36}$ Coil-rod-coil ABA triblock copolymers with pendent PEG chains have been prepared by a Heck coupling 
strategy ${ }^{37}$ and ferrocene containing $\mathrm{ABC}$ triblock copolymers have been made by an anionic polymerisation-Wittig olefination approach. ${ }^{38}$ These strategies all involve complex multistep syntheses and lead to poor control over the molecular weight distribution.

In this study we report a precisely controlled approach to the synthesis of conjugated triblock copolymers, ${ }^{23}$ by the ROMP of cyclophanediene monomers M1 and M2 with bifunctional ruthenium complex $\mathbf{1}$ to form the telechelic polymer intermediate [I] (Fig. 1). Trapping of this intermediate with a second cyclophanediene gives the fully conjugated rod-rodrod ABA triblock copolymer. Quenching of the intermediate $[\mathbf{I}]$ with an $\alpha$-bromoester functionalised vinylether $\mathbf{E}$ followed by ATRP of the resulting macroinitiator generates coil-rod-coil ABA triblock copolymers. This approach can be extended to the synthesis of the corresponding pentablock copolymers. To our knowledge this is the first bidirectional ROMP ${ }^{39}$ of paracyclophanedienes using bifunctional ruthenium carbene initiators towards the synthesis of conjugated multiblock copolymers (Fig. 1).

\section{Results and discussion}

Initial optimisation studies focussed on the ROMP of monomers M1 and M2 using the bifunctional catalyst 1 . The required cyclophane-1,9-diene monomers $\mathbf{M 1}(\mathrm{R}=O$-2-ethylhexyl $)^{33}$ and $\mathbf{M} 2(\mathrm{R}=n \text {-octyl })^{40}$ were prepared using standard synthetic procedures. The bifunctional catalyst 1 was synthesised by cross metathesis of Grubbs second generation catalyst G2 with 2,5-dimethoxy-1,4-divinylbenzene as reported. ${ }^{41}$

The first ROMP experiment was performed using dialkoxy monomer M1 $([\mathbf{M} 1] /[\mathbf{1}]=10)$ in DCM- $d_{2}$ at room temperature. The polymerisation was followed by in situ ${ }^{1} \mathrm{H}$ NMR spectroscopy and complete monomer consumption was observed after $63 \mathrm{~h}$. However, reaction times were reduced to $10 \mathrm{~h}$ when the ROMP was performed at $60{ }^{\circ} \mathrm{C}$ in TCE- $d_{2}$ (Fig. S3 $\dagger$ ). After consumption of the monomer the polymerisation was

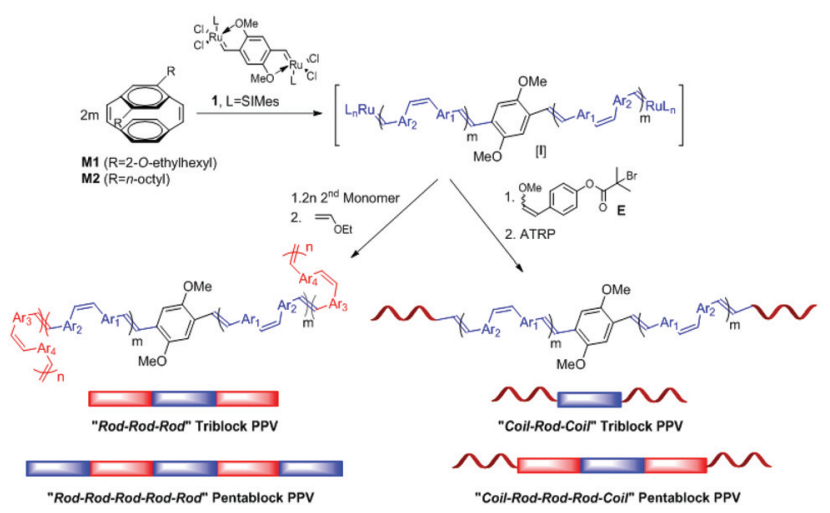

Fig. 1 A bidirectional ROMP of strained paracyclophanediene monomers to both partially and fully conjugated tri and pentablock copolymers. quenched with excess ethylvinylether and stirred at $\mathrm{rt}$ for $4 \mathrm{~h}$. Precipitation of the crude product ( $\mathrm{MeOH} / \mathrm{Celite})$, followed by elution with chloroform gave telechelic PPV 2a $\left(M_{\mathrm{n} \text { (calc.) }}=\right.$ $\left.4.7 \mathrm{kDa}, M_{\mathrm{n}(\mathrm{obs})}=5.7 \mathrm{kDa}, D_{\mathrm{m}}=1.40\right)$ in $95 \%$ yield (entries 1 and 2, Table S1 $\dagger$ ).

Bidirectional ROMP of the dialkyl monomer M2 ([M2]/[1] = 10) in DCM- $d_{2}$ at room temperature was complete in $1.5 \mathrm{~h}$ but gave poor control over the molecular weight distribution $\left(M_{\mathrm{n} \text { (calc.) }}=4.4 \mathrm{kDa}, M_{\mathrm{n}(\mathrm{obs})}=79 \mathrm{kDa}, D_{\mathrm{m}}=1.8\right)$ due to incomplete initiation and fast propagation. The higher propagation rates are due to the absence of Lewis basic sites in monomer M2 that can ligate to the intermediate 14 electron ruthenium complex formed after initiation. Therefore, the ROMP was performed in the presence of an external ligand 3-BrPy (40 mol\%) at $40{ }^{\circ} \mathrm{C}$ in TCE- $d_{2}$ for $20 \mathrm{~h}$ (Fig. S4 $\dagger$ ) to slow down propagation. This gave PPV 3a with significant control over molecular weight $\left(M_{\mathrm{n}(\mathrm{obs} .)} \sim 7.1 \mathrm{kDa} v s .79 \mathrm{kDa}\right.$ in the absence of 3-BrPy, entries 3 and 4, Table S1 $\dagger$ ). Further control over the molecular weight and an improved yield was obtained $\left(M_{\mathrm{n}(\mathrm{obs} .)} \sim\right.$ $5.4 \mathrm{kDa})$ when the ROMP was performed at $40{ }^{\circ} \mathrm{C}$ using anhydrous degassed DCM as solvent (entries 4 and 5, Table S2 $\dagger$ ). This could be due to the better solubility of 1 in DCM. The living nature of the polymerisation was demonstrated by varying the [monomer]/[initiator] ratio to obtain polymers $2 \mathbf{2}-\mathbf{c}$ (96-93\% yield) and $3 \mathbf{3 a - c}(95-81 \%$ yield) as shown in Fig. 2 (also, see Table S2 $\dagger$ ). The $[\mathbf{M}] /[\mathbf{I}]$ ratios given for the monomers M1 and M2 are different because ROMP of M1 under the optimal conditions gives poor control of the molecular weight and dispersity beyond ratios of $20: 1$.

A powerful application of this bidirectional ROMP methodology was demonstrated by the synthesis of both rod-rod-rod and coil-rod-coil triblock copolymers. Triblock conjugated copolymers have found interesting application as the active layer in OPV and OLED devices ${ }^{42}$ but only limited synthetic

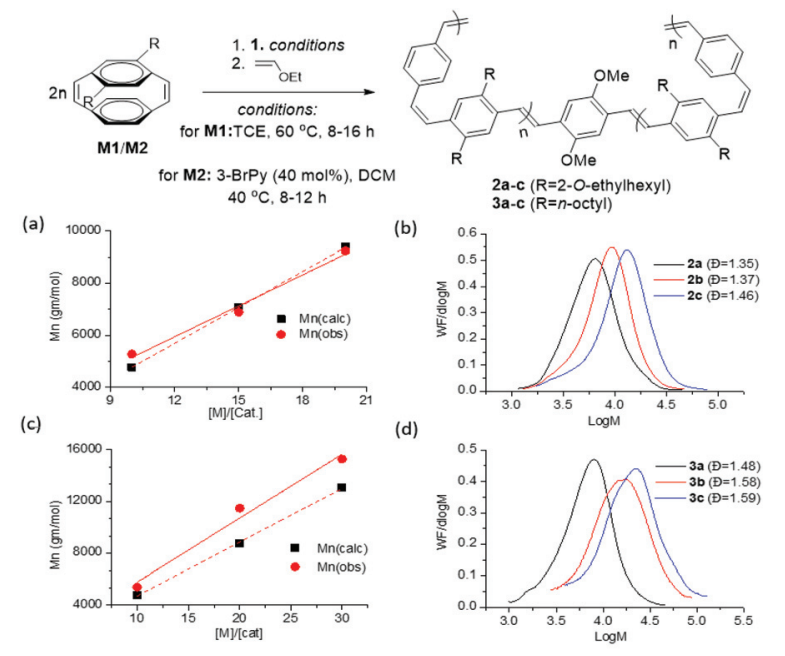

Fig. 2 Bidirectional ROMP of monomers M1 and M2 with initiator 1. (a) and (c) dependence of $M_{n}$ of the polymers $2 a-c$ and $3 a-c$ on [M]/[1] ratio, (b) and (d) molecular weight distribution of polymers $2 a-c$ and $3 a-c$ respectively. 
methods have been reported. $\mathrm{AB}$ and $\mathrm{ABA}$ block copolymers with PPV units are known to self-assemble into nanostructures, the morphology of which depends on the mole fraction of the individual blocks. ${ }^{9,43}$

The $\alpha$-bromoester end capped PPV macroinitaitors $4 a$ and 5a were prepared in excellent yields (95-98\%) by bidirectional ROMP of monomers M1 and M2 followed by quenching with $\alpha$-bromoester phenyl methylvinyl ether $\mathbf{E}(f=89 \%$ and $75 \%$, see Table S2 $\dagger$ ). Matrix-assisted laser desorption/ionization time-of-flight mass spectrometry (MALDI-TOF-MS) of polymer 4a and 5a showed major peaks corresponding to the desired polymers with $\alpha$-bromoester end groups ( $)$, the major series of peaks separated by the mass of the polymer repeat unit 461.4 Da and 428.9 Da corresponding to the molecular weights of monomers M1 and $\mathbf{M} 2$ respectively (Fig. 3, S19 $\dagger$ ). ${ }^{44}$

These macroinitiators (4a and $\mathbf{5 a}$ ) were subjected to $\mathrm{CuBr}$ mediated atom transfer radical polymerisation (ATRP) ${ }^{33}$ with methyl methacrylate (MMA) in hot toluene for $3 \mathrm{~h}$. Aliquots of the reactions were terminated at different time intervals $(30$, $90,180 \mathrm{~min}$ ) by exposing to air followed by precipitation into excess methanol. The solids were redissolved in chloroform and precipitated by addition of diethyl ether. Upon filtration, PMMA- $b$-PPV- $b$-PMMA triblock polymers $\mathbf{6 a - c}$ and $7 \mathbf{a}-\mathbf{c}$ were obtained as orange/yellow solids with dispersities ranging from 1.23 to 1.33 and a unimodal molar mass distribution by GPC analysis (Scheme 1, Fig. S21 and Table S3†).

The MMA content in these triblock copolymers was determined from the ${ }^{1} \mathrm{H}$ NMR spectra by a comparison of the integration of the OMe group of MMA $(\delta=3.98-3.17 \mathrm{ppm})$ against the combined phenyl and vinylene protons for $\mathbf{6 a - c}(\delta=$ 7.93-6.34 ppm) and methylene protons for 7a-c $(\delta=$ 2.86-2.16 ppm) respectively (Fig. S22-27, Table S3†).

Bidirectional living polymerisation of cyclophanedienes in a sequential manner gave fully conjugated triblock copolymers. ROMP of monomer M1 with initiator $\mathbf{1}([\mathbf{M 1}] /[\mathbf{1}]=10)$ in TCE at $60{ }^{\circ} \mathrm{C}$ was monitored by GPC and TLC analyses (Fig. S47†). After complete consumption ( $t=8 \mathrm{~h}$ ) of monomer M1 an external ligand, 3-BrPy (40 mol\%), and a solution of the second monomer $\mathbf{M} 2$ in TCE were added. The reaction mixture was stirred at $40{ }^{\circ} \mathrm{C}$ until the second monomer M2 was consumed ( $t=12,16$ and $18 \mathrm{~h}$ ) and the polymerisation was quenched with excess ethylvinylether. Purification by precipitation (Celite/MeOH) and elution with chloroform afforded fully conjugated ABA triblock polymers $\mathbf{8 a - c}$ in $80-88 \%$ yields

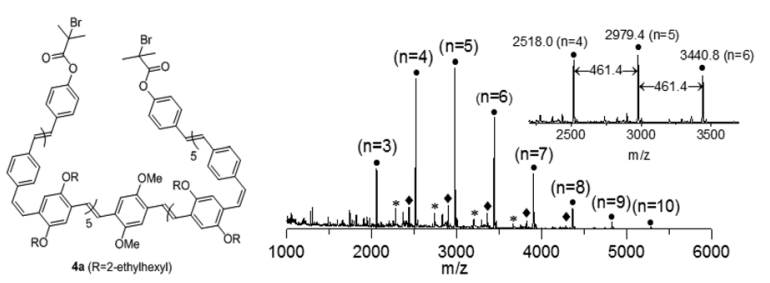

Fig. 3 MALDI-TOF-MS of macroinitiator $4 a(\bullet)$ peaks correspond to $\alpha$-bromoester end groups (*) phenol with elimination of $\mathrm{HBr}$ and $(\downarrow)$ $\mathrm{PPV}$ with elimination of $\mathrm{HBr}$.

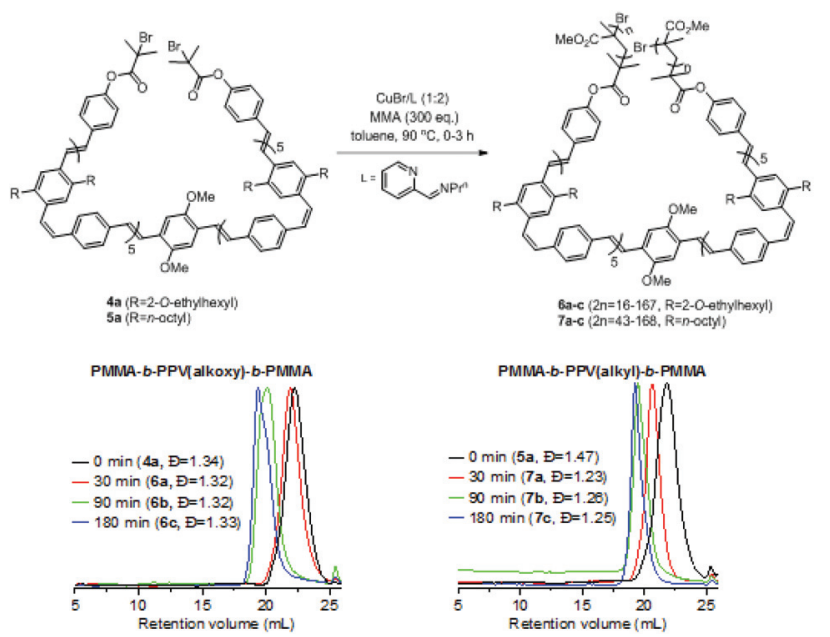

Scheme 1 ROMP-ATRP strategy to prepare coil-rod-coil ABA phenylenevinylene triblock copolymers $6 a-c$ and $7 a-c$ (GPC in THF).

with dispersities ranging from 1.87-1.97. The higher polydispersities and the shoulder peak observed in the GPC traces of block copolymer $\mathbf{8 c}$ can be assigned to partial isomerisation of the cis-alkenes (Scheme 2, left and Table S4 $\dagger$ ). The sequential ROMP strategy was more efficient (yields $93-97 \%$ and $\emptyset_{\mathrm{m}}=$ 1.35-1.87) when the monomer addition sequence was reversed to give BAB triblock copolymers 9a-c containing alkyl PPV segments at the center and alkoxy PPV units on either side (Fig. S48, $\uparrow$ Scheme 2, right and Table S4 $\dagger$ ).

The triblock copolymers $\mathbf{8 a - c}$ and $\mathbf{9 a - c}$ were characterised by ${ }^{1} \mathrm{H}$ NMR spectroscopy and the ratio of monomer units M1 and $\mathbf{M} 2$ incorporated was calculated by combined integration of the alkoxy methylene protons corresponding to $\mathbf{M 1}$ and the methoxy protons of $\mathbf{1}(\delta$ 4.12-3.77 ppm) against the benzyl

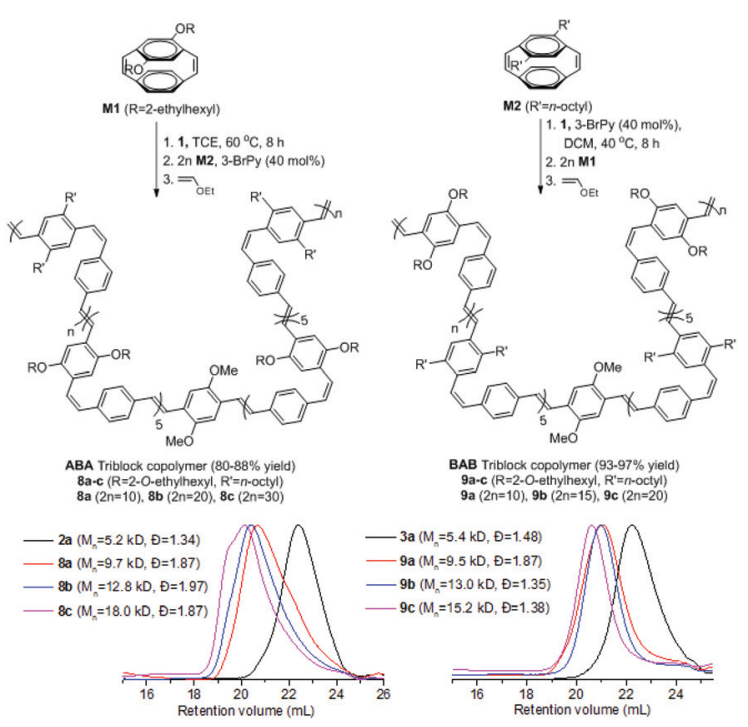

Scheme 2 Sequential ROMP strategy to fully conjugated rod-rod-rod ABA $(8 a-c)$ and BAB $(9 a-c)$ phenylenevinylene triblock copolymers (GPC in THF). 
protons corresponding to $\mathbf{M} 2(\delta 2.72-2.20 \mathrm{ppm})$ (Fig. S31-41†). The individual block content ratios determined from the ${ }^{1} \mathrm{H}$ NMR spectra were in good correlation with the calculated values based on the monomer to initiator ratio (Table S4 $\uparrow$ ).

${ }^{1} \mathrm{H}$ NMR spectral analysis of the BAB triblock copolymers 9a-c (Fig. S37†) indicated high vinyl end-capping efficiency $(f>80 \%)$ suggesting that further functionalisation/elaboration could be possible. Therefore the sequential ROMP was quenched with the $\alpha$-bromoester substituted phenylmethyl ether $\mathbf{E}$ instead of ethyl vinylether to give the bifunctional triblock PPV macroinitiator $\mathbf{1 0}$ in excellent yield with excellent end capping efficiency (95\% yield, $f>87 \%$ ). Under similar ATRP reaction conditions to those in Scheme 1 the macroinitiator 10 and MMA gave coil-rod-rod-rod-coil CBABC pentablock copolymers 11a-c with molecular weights ranging from 20.6-36.5 $\mathrm{kDa}$ and dispersities in the range 1.49-1.25. The slightly broader dispersity of 11a is due to partial isomerisation of the cis-alkenes (Scheme 3, Table S3 and Fig. S28-30†).

Furthermore the sequential ROMP approach can be used to synthesise fully conjugated pentablock copolymers as shown in Scheme 4. Dialkyl monomer M2 was subjected to ROMP

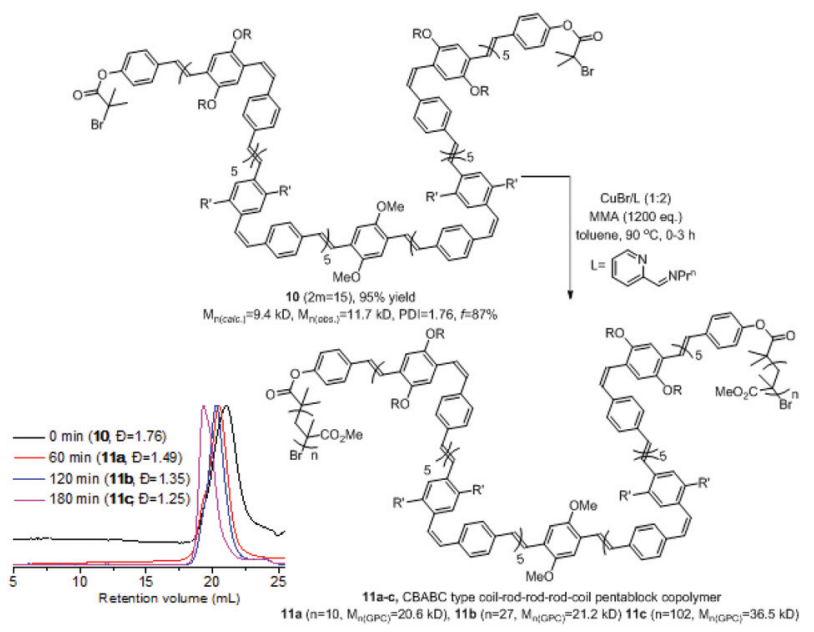

Scheme 3 Sequential ROMP-ATRP strategy to coil-rod-rod-rod-coil CBABC pentablock copolymers 11a-c (GPC in THF).

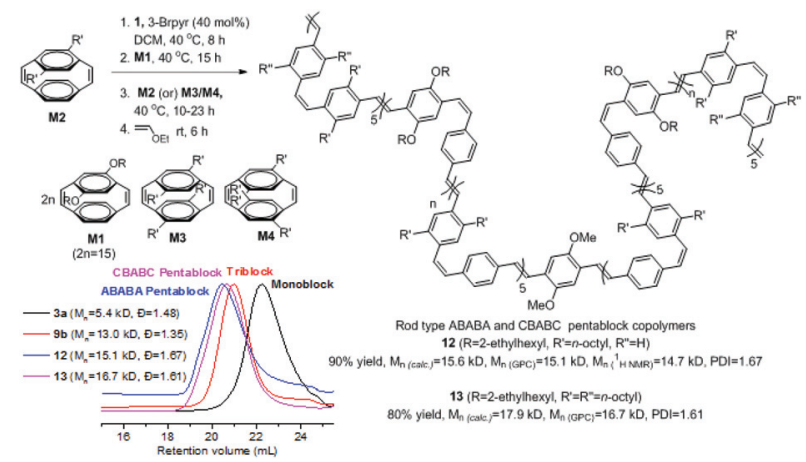

Scheme 4 Sequential ROMP strategy to fully conjugated rod ABABA 12 and CBABC 13 pentablock copolymers (GPC in THF).
$([\mathbf{M} 2] /[1]=10)$ in the presence of 3-BrPy ligand and upon complete consumption the dialkoxy monomer M1 was added and stirred for $15 \mathrm{~h}$, complete consumption of this monomer (M1) was followed by addition of either $\mathbf{M 2}$ or a mixture of the isomeric tetraalkyl monomers M3, M4 (M4 being unreactive). The polymerisation reaction was eventually quenched by adding excess ethylvinyl ether and the fully conjugated $A B A B A$ and CBABC type pentablock copolymers $\mathbf{1 2}$ and $\mathbf{1 3}$ were isolated by precipitation (Scheme 4, S43 \& S45†).

Dilute solutions of conjugated polymers $\mathbf{2 a - c}, \mathbf{3 a - c}, \mathbf{8 a - c}$, 9a-c, 12 and $\mathbf{1 3}$ in degassed anhydrous dichloromethane were subjected to photoisomerisation under UV irradiation at $365 \mathrm{~nm}$ for $48-72$ h. ${ }^{1} \mathrm{H}$ NMR analysis of the polymers obtained indicated complete isomerisation and an all trans geometry of the backbone vinylenes (Fig. $4 \mathrm{a}$, also see ESI†े). In the GPC a lower retention time was observed for the all trans isomers as expected because of the higher hydrodynamic volume of this polymer (Fig. 4b).

The optical properties of the parent homopolymers were measured in solution (Fig. S49 and Table S5 $\dagger$ ) and the block copolymers were recorded in both solution and as thin films (Fig. 5, S50-54, and Table S5†). The absorption spectra of the fully conjugated tri and pentablock copolymers $\mathbf{8 a}-\mathbf{c}, \mathbf{9 a}-\mathbf{c}, 12$ and 13 showed $\lambda_{\max }$ values around $450 \mathrm{~nm}$ and $380 \mathrm{~nm}$ correlating to absorptions of the individual blocks $2 \mathbf{a}-\mathbf{c}$ and $3 \mathbf{a}-\mathbf{c}$. Increasing the content of monomer $\mathbf{M 2}$ in polymers $\mathbf{8 a}$ to $\mathbf{8 c}$ increased the intensity at $370 \mathrm{~nm}$ in direct correlation with the ratio of the individual blocks (Fig. 5a). For polymers 9a-c the absorption maxima were red shifted going from $9 a$ to $9 \mathbf{c}$ with

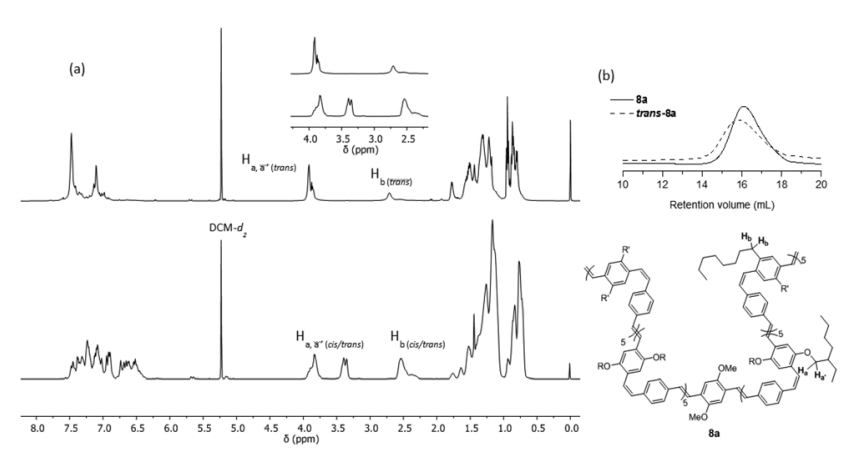

Fig. 4 Photoisomerisation of triblock copolymer $8 a$, (a) ${ }^{1} \mathrm{H}$ NMR spectra of $8 a$ and trans $-8 \mathrm{a}$ in DCM- $d_{2}$, (b) GPC traces of $8 \mathrm{a}$ and trans-8a in $\mathrm{CHCl}_{3}$.
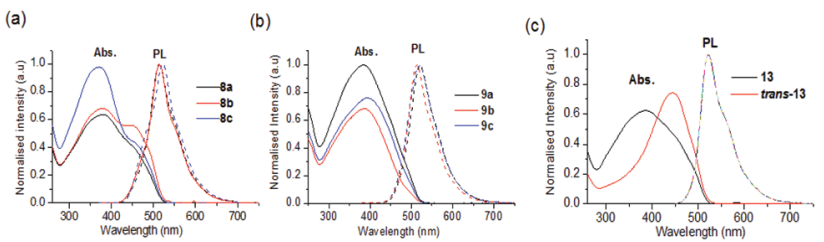

Fig. 5 Absorption and emission profiles of rod (a) $A B A$ triblock (b) BAB triblock and (c) CBABC pentablock copolymers. 
increasing alkoxy monomer content (Fig. 5b). Excitation of the block copolymer 8a-c, 9a-c, 12 and $\mathbf{1 3}$ at $370 \mathrm{~nm}$ and the corresponding all trans isomers at $440 \mathrm{~nm}$ resulted in emission maxima approximately at $520 \mathrm{~nm}$ (Table S5†).

The absorption and emission spectra of rod-coil block copolymers 6a-c, 7a-c and 11a-c showed absorption maxima at $460 \mathrm{~nm}(\mathbf{6 a}-\mathbf{c}), 400 \mathrm{~nm}(7 \mathbf{a}-\mathbf{c}), 370 \mathrm{~nm}(\mathbf{1 1 a}-\mathbf{c})$ and emission maxima at $527 \mathrm{~nm}$ (6a-c), $491 \mathrm{~nm}$ (7a-c) and $520 \mathrm{~nm}(\mathbf{1 1 a}-\mathbf{c})$. These values agree well with those of parent macroinitiators 4a, 5a and 10, indicating that the PMMA block has no influence on the optical properties of these materials. The $\Phi_{\mathrm{PL}}$ of the macroinitiators $\mathbf{4 a}, \mathbf{5 a}$ and $\mathbf{1 0}$ and the block copolymers 7a-c, 8a-c and 11a-c are identical and this suggests that the radical polymerisation did not perturb the $\pi$-conjugated backbone (Table $55 \dagger$ ). A small red shift in emission maxima values $(\sim 20 \mathrm{~nm})$ was observed in the solid state spectra of the block copolymers consistent with previous studies on PPV polymers (Fig. S53-54 and Table S6†). ${ }^{28}$

The electrochemical properties of the homopolymers (2a-c and $\mathbf{3 a - c}$ ) and fully conjugated block copolymers $(\mathbf{8 a}-\mathbf{c}, \mathbf{9 a}-\mathbf{c}$, 12 and 13) were studied by cyclic voltammetry in dichloromethane using $\left[\left(\mathrm{C}_{4} \mathrm{H}_{9}\right)_{4} \mathrm{~N}\right] \mathrm{PF}_{6}(0.1 \mathrm{M}$ solution in DCM $)$ as the electrolyte in conjunction with a platinum working electrode. The calculated HOMO and LUMO energy levels for $2 \mathbf{a}-\mathbf{c}$ are consistent with the reported values (HOMO $=-5.14$ and LUMO $=-2.56 \mathrm{eV}$ ) for these polymers. ${ }^{28}$ The homopolymers 3a-c have deeper HOMO levels $(\sim-5.36 \mathrm{eV})$ (Table 1 , entries 1 \& 3 and Table $\mathrm{S} 7 \dagger$ ).

The HOMO and LUMO energy levels of the tri- and pentablock copolymers are consistent with those of the parent homopolymers. The cis/trans ABA triblock BCPs 8a-c exhibited reversible oxidation $E_{1 / 2}$ values in the range of $0.6-0.4 \mathrm{~V}$, with slight increase in HOMO energy levels $(-5.23$ to $-5.05 \mathrm{eV})$ but the BCPs 9a-c showed the same HOMO value $(\sim-5.14 \mathrm{eV})$ indi-

Table 1 Electrochemical properties of homopolymers (2a \& 3a) and block copolymers ( $8 a-c, 9 a-c, 12$ \& 13)

\begin{tabular}{lllll}
\hline Entry & Polymer & $\mathrm{HOMO}^{a}(\mathrm{eV})$ & $\mathrm{LUMO}^{b}(\mathrm{eV})$ & $E_{\mathrm{g}(\mathrm{elc})}{ }^{c, d}(\mathrm{eV})$ \\
\hline 1 & $\mathbf{2 a}$ & -5.14 & -2.66 & $2.48(2.30)$ \\
2 & $\mathbf{2 a}(\mathbf{E})$ & -5.01 & -2.84 & $2.17(2.28)$ \\
3 & $\mathbf{3 a}$ & -5.36 & -2.58 & $2.78(2.50)$ \\
4 & $\mathbf{3 a}(\mathbf{E})$ & -5.10 & -2.81 & $2.29(2.46)$ \\
5 & $\mathbf{8 a}$ & -5.23 & -2.77 & $2.46(2.31)$ \\
6 & $\mathbf{8 b}$ & -5.12 & -2.69 & $2.43(2.27)$ \\
7 & $\mathbf{8 c}$ & -5.05 & -2.78 & $2.27(2.27)$ \\
8 & $\mathbf{8 b}(\mathbf{E})$ & -5.03 & -2.70 & $2.33(2.29)$ \\
9 & $\mathbf{9 a}$ & -5.10 & -2.67 & $2.43(2.33)$ \\
10 & $\mathbf{9 b}$ & -5.14 & -2.66 & $2.48(2.32)$ \\
11 & $\mathbf{9 c}$ & -5.14 & -2.60 & $2.54(2.30)$ \\
12 & $\mathbf{9 a}(\mathbf{E})$ & -5.02 & -2.75 & $2.27(2.30)$ \\
13 & $\mathbf{1 2}$ & -5.14 & -2.64 & $2.50(2.34)$ \\
14 & $\mathbf{1 2}(\mathbf{E})$ & -5.04 & -2.69 & $2.35(2.29)$ \\
15 & $\mathbf{1 3}$ & -5.19 & -2.79 & $2.40(2.31)$ \\
16 & $\mathbf{1 3}(\mathbf{E})$ & -5.05 & -2.67 & $2.38(2.28)$
\end{tabular}

${ }^{a} \mathrm{HOMO}=\left(E_{\mathrm{ox}}^{\mathrm{onset}}-\mathrm{Fc}_{\mathrm{ox}}\right)+4.8 .{ }^{b} \mathrm{LUMO}=\left(\mathrm{E}_{\mathrm{red}}^{\text {onset }}-\mathrm{Fc}_{\mathrm{ox}}\right)+4.8 .{ }^{c} E_{\mathrm{g}}$ (elc. $)=$ HOMO-LUMO. ${ }^{d}$ Optical band gap values in parenthesis $\left(E_{\mathrm{g}}\right.$ (opt.) $=$ $\left.1240 / \lambda_{\text {onset }}\right)$. cating localisation of the HOMO on the dialkoxyphenylene vinylene block in 9a-c. The LUMO energy levels for BCPs 8a-c and $\mathbf{9 a}-\mathbf{c}$ are in a similar range, -2.69 to $-2.78 \mathrm{eV}$ for $\mathbf{8 a}-\mathbf{c}$ and -2.60 to $-2.67 \mathrm{eV}$ for $9 \mathrm{a}-\mathrm{c}$ (Table $\mathrm{S} 7 \dagger$ and Table 1 , entries $5-7$ \& 9-11). The cis/trans pentablock copolymers 12 and 13 showed reversible oxidation and reduction potentials $E_{1 / 2}$ at $0.5-0.6 \mathrm{~V}$ and $-1.99,-1.80 \mathrm{~V}$ with the HOMO energy level approximately $-5.14 \mathrm{eV}$ but slightly deeper LUMO level $(-2.79 \mathrm{eV})$ for BCP 13 (Table S7† and Table 1, entries $13 \& 15)$. In general, the all trans homo and block copolymers have a higher lying HOMO when compared to their cis/trans forms due to extended conjugation in the trans form. Also, a consistent deepening of LUMO levels was observed for all the trans polymers except for trans-13 (Table 1, entries 15 \& 16). Finally, a clear trend in bandgap reduction was observed for the all trans polymers due to extended delocalisation and both the electrochemical and optical bandgap values for all the polymers are comparable (Table 1).

\section{Conclusions}

In summary, the first bidirectional ROMP of strained paracyclophane-1,9-dienes using a bifunctional Hoveyda-Grubbs initiator is reported. This methodology was used in the controlled synthesis of rod-rod and rod-coil tri- and pentablock copolymers through sequential ROMP and ROMP-ATRP reactions. The initially formed cis,trans polymers can be photoisomerised to the corresponding all trans forms. The optical properties of the block copolymers directly correlate with those of the individual polymer blocks and complete energy transfer between blocks is observed in the fluorescence emission spectra of thin films. Fluorescence quantum efficiency measurements of the rod-coil block copolymers showed no damage to $\pi$-conjugated backbone under radical ATRP reaction conditions.

\section{Conflicts of interest}

There are no conflicts to declare.

\section{Acknowledgements}

The authors would like to thank the European Commission for the award of a Marie-Curie International Fellowship (CyclAr) to VK, the Indian High Commission Education Wing, London for PhD studentship to DRK (11015/16/2012-SCD-V) and the EPSRC for a studentship award to BJL. The authors would also like to thank the EPSRC for funding of the NMR spectrometers under grant EP/K039547/1 and Dr Ralph Adams, Mr Carlo Bawn for technical advice and Mr Adam Woodward for his technical support in measuring fluorescence quantum yields. 


\section{References}

1 A. C. Grimsdale, K. Leok Chan, R. E. Martin, P. G. Jokisz and A. B. Holmes, Chem. Rev., 2009, 109, 897-1091.

2 L. Dou, Y. Liu, Z. Hong, G. Li and Y. Yang, Chem. Rev., 2015, 115, 12633-12665.

3 Y. He, W. Hong and Y. Li, J. Mater. Chem. C, 2014, 2, 86518661.

4 L. Ying, F. Huang and G. C. Bazan, Nat. Commun., 2017, 8, 14047.

5 L. Lu, T. Zheng, Q. Wu, A. M. Schneider, D. Zhao and L. Yu, Chem. Rev., 2015, 115, 12666-12731.

6 D. Khim, G.-S. Ryu, W.-T. Park, H. Kim, M. Lee and Y.-Y. Noh, Adv. Mater., 2016, 28, 2844-2844.

7 C. Zhang, P. Chen and W. Hu, Chem. Soc. Rev., 2015, 44, 2087-2107.

8 J. R. Sheats and P. F. Barbara, Acc. Chem. Res., 1999, 32, 191-192.

9 M. Lee, B.-K. Cho and W.-C. Zin, Chem. Rev., 2001, 101, 3869-3892.

10 F. Mathias, A. Fokina, K. Landfester, W. Tremel, F. Schmid, K. Char and R. Zentel, Macromol. Rapid Commun., 2015, 36, 959-983.

11 M. He, F. Qiu and Z. Lin, J. Mater. Chem., 2011, 21, 1703917048.

12 S. Miyane, H. Mori and T. Higashihara, Microsyst. Technol., 2016, 22, 3-10.

13 J. Wang, M. Ueda and T. Higashihara, ACS Macro Lett., 2013, 2, 506-510.

14 M. Verswyvel, J. Steverlynck, S. Hadj Mohamed, M. Trabelsi, B. Champagne and G. Koeckelberghs, Macromolecules, 2014, 47, 4668-4675.

15 K. B. Woody, B. J. Leever, M. F. Durstock and D. M. Collard, Macromolecules, 2011, 44, 4690-4698.

16 C. W. Bielawski, T. Morita and R. H. Grubbs, Macromolecules, 2000, 33, 678-680.

17 G. Qu, F. Jiang, S. Zhang and S. Usuda, Mater. Lett., 2007, 61, 3421-3424.

18 H. Wang, W. You, P. Jiang, L. Yu and H. H. Wang, Chem. Eur. J., 2004, 10, 986-993.

19 L. zur Borg, A. L. Domanski, R. Berger and R. Zentel, Macromol. Chem. Phys., 2013, 214, 975-984.

20 C.-Y. Yu and M. L. Turner, Angew. Chem., 2006, 118, 79617964.

21 A. M. Spring, C.-Y. Yu, M. Horie and M. L. Turner, Chem. Commun., 2009, 2676-2678.

22 C.-Y. Yu, M. Helliwell, J. Raftery and M. L. Turner, Chem. Eur. J., 2011, 17, 6991-6997.

23 B. J. Lidster, D. R. Kumar, A. M. Spring, C.-Y. Yu and M. L. Turner, Polym. Chem., 2016, 7, 5544-5551.
24 D. R. Kumar, B. J. Lidster, R. W. Adams and M. L. Turner, Polym. Chem., 2017, 8, 3186-3194.

25 S.-W. Chang and M. Horie, Chem. Commun., 2015, 5, 91139116.

26 D. Mäker, C. Maier, K. Brödner and U. H. F. Bunz, ACS Macro Lett., 2014, 415-418.

27 F. Menk, M. Mondeshki, D. Dudenko, S. Shin, D. Schollmeyer, O. Ceyhun, T.-L. Choi and R. Zentel, Macromolecules, 2015, 48, 7435-7445.

28 C.-Y. Yu, M. Horie, A. M. Spring, K. Tremel and M. L. Turner, Macromolecules, 2009, 43, 222232.

29 C. Y. Yu, J. W. Kingsley, D. G. Lidzey and M. L. Turner, Macromol. Rapid Commun., 2009, 30, 1889-1892.

30 F. Menk, S. Shin, K.-O. Kim, M. Scherer, D. Gehrig, F. Laquai, T.-L. Choi and R. Zentel, Macromolecules, 2016, 49, 2085-2095.

31 E. Elacqua, G. T. Geberth, D. A. Vanden Bout and M. Weck, Chem. Sci., 2019, 10, 2144-2152.

32 S. K. Pomarico, D. S. Lye, E. Elacqua and M. Weck, Polym. Chem., 2018, 9, 5655-5659.

33 B. J. Lidster, J. M. Behrendt and M. L. Turner, Chem. Commun., 2014, 50, 11867-11870.

34 I. Cosemans, J. Vandenbergh, L. Lutsen, D. Vanderzande and T. Junkers, Polym. Chem., 2013, 4, 3471-3479.

35 K. Nomura, T. Haque, T. Onuma, F. Hajjaj, M. S. Asano and A. Inagaki, Macromolecules, 2013, 46, 9563-9574.

36 G. Tu, H. Li, M. Forster, R. Heiderhoff, L. J. Balk and U. Scherf, Macromolecules, 2006, 39, 4327-4331.

37 H. Wang, H. H. Wang, V. S. Urban, K. C. Littrell, P. Thiyagarajan and L. Yu, J. Am. Chem. Soc., 2000, 122, 6855-6861.

38 F. He, T. Gädt, M. Jones, G. D. Scholes, I. Manners and M. A. Winnik, Macromolecules, 2009, 42, 7953-7960.

39 P. Lu, N. M. Alrashdi and A. J. Boydston, J. Polym. Sci., Part A: Polym. Chem., 2017, 55, 2977-2982.

40 B. J. Lidster, D. R. Kumar, A. M. Spring, C.-Y. Yu, M. Helliwell, J. Raftery and M. L. Turner, Org. Biomol. Chem., 2016, 14, 6079-6087.

41 K. Grudzień, M. Malinska and M. Barbasiewicz, Organometallics, 2012, 31, 3636-3646.

42 R. A. Segalman, B. McCulloch, S. Kirmayer and J. J. Urban, Macromolecules, 2009, 42, 9205-9216.

43 N. Sary, L. Rubatat, C. Brochon, G. Hadziioannou, J. Ruokolainen and R. Mezzenga, Macromolecules, 2007, 40, 6990-6997.

44 It is common that the $M_{\mathrm{n}}$ values obatined from GPC do not correlate with MALDI-TOF-MS data especially for polydisperse polymers, see: H. Rashidzadeh and B. Guo, Anal. Chem., 1998, 70, 131-135. 